\title{
Effect of silibinin on endothelial dysfunction and ADMA levels in obese diabetic mice
}

\author{
Giovanni Li Volti ${ }^{1,2 \dagger}$, Salvatore Salomone ${ }^{3 \dagger}$, Valeria Sorrenti ${ }^{1}$, Andrea Mangiameli ${ }^{4}$, Vincenzo Urso ${ }^{3}, \| l i a s$ Siarkos $^{3}$, \\ Fabio Galvano ${ }^{1}$ and Federico Salamone ${ }^{4^{*}}$
}

\begin{abstract}
Background: Cardiovascular diseases (CVD) in diabetic patients have endothelial dysfunction as a key pathogenetic event. Asymmetric dimethylarginine (ADMA), an endogenous inhibitor of nitric oxide synthase (NOS), plays a pivotal role in endothelial dysfunction. Different natural polyphenols have been shown to preserve endothelial function and prevent CVD. In this study, we assessed the effect of silibinin, a widely used flavonolignan from milk thistle, on ADMA levels and endothelial dysfunction in $\mathrm{db} / \mathrm{db}$ mice.

Methods: Eight-week-old db/db mice were administrated a $20 \mathrm{mg} / \mathrm{Kg}$ i.p. daily dose of silibinin $(n=6)$ or vehicle $(n=6)$ for four weeks. Heterozygous lean $\mathrm{db} / \mathrm{m}$ mice served as control. Plasma, aorta and liver ADMA levels were determined by ELISA. Vascular reactivity to phenilephrine (PE), acetylcholine (ACh), sodium nitroprusside (SNP) and ADMA was assessed in isolated aortic segments, in wire myograph.

Results: Plasma and aorta ADMA levels were higher in $\mathrm{db} / \mathrm{db}$ than in control lean mice. Silibinin administration markedly decreased plasma ADMA; consistently, aorta ADMA was reduced in silibinin-treated animals. Plasma and aorta ADMA levels exhibited a positive correlation, whereas liver ADMA was inversely correlated with both plasma and aorta ADMA concentrations. Endothelium-(NO)-dependent vasodilatation to ACh was impaired in db/db mice and was restored in the silibinin group, in accordance with the observed reduction of plasma and vascular levels of ADMA. Endothelium-independent vasodilatation to SNP was not modified by silibinin administration; contractile tone induced in isolated aorta from $\mathrm{db} / \mathrm{db}$ mice by challenging with exogenous ADMA was not affected by the treatment.
\end{abstract}

Conclusions: Silibinin markedly improves endothelial dysfunction in $\mathrm{db} / \mathrm{db}$ mice by reducing circulating and vascular ADMA levels. Clinical studies are warranted to assess the efficacy of silibinin for cardiovascular protection.

Keywords: diabetes, silibinin, db/db, endothelial dysfunction, ADMA, vascular reactivity

\section{Background}

Cardiovascular diseases (CVD) are a leading cause of death worldwide and are tightly related to obesity, diabetes and the full spectrum of the metabolic syndrome [1]. Endothelial dysfunction is a main event in the pathogenetic cascade conducing to cardiovascular events [2] and therapies aiming at preserving endothelium are needed for the effective prevention of CVD. Endothelium plays a central role in the physiological maintenance of vascular function by regulating vascular tone,

\footnotetext{
* Correspondence: federicosalamone@yahoo.it

+ Contributed equally

${ }^{4}$ Department of Internal Medicine, University of Catania, Catania, Italy

Full list of author information is available at the end of the article
}

leukocyte adhesion and platelet activation, as a result of release of vasoactive substances such as nitric oxide (NO), prostacyclin and endothelin [3].

Several natural polyphenols have been evaluated for their ability to preserve endothelial function and thus for their effectiveness in preventing CVD [4]. Recently, silibinin, a polyphenolic compound contained in silymarin, has been demonstrated to exert in vitro protective effects on endothelial cells [5]; however, it is not clear whether silibinin may exert vascular protective effect in vivo.

In the diabetic status, vascular dysfunction is mainly related to decreased NO bioavailability [6]. Previous studies showed that endogenous arginine analogs may play

\section{() Biomed Central}


a regulatory role in the arginine/NO pathway [7]. Asymmetric $\mathrm{N}^{\mathrm{G}}, \mathrm{N}^{\mathrm{G}}$-dimethyl-L-arginine (ADMA) is an endogenous inhibitor of all isoforms of Nitric Oxide Synthase (NOS). Several evidences suggest that ADMA exerts deleterious vascular effects by inhibiting endothelial NOS (eNOS). Elevated ADMA levels have been identified as a biomarker of endothelial dysfunction [8]. Interestingly, circulating ADMA is significantly correlated with carotid artery intima-media thickness [9], and ADMA increase precedes the occurrence of vascular occlusive disease [10]. Taken together, these observations suggest that plasma ADMA is significantly associated with cardiovascular risk. ADMA metabolism is related to its generation from protein breakdown and to its cleavage by dimethylarginine hydrolase (DDAH) into citrulline and dimethylamine [11].

The liver is a main regulator of circulating ADMA levels [12]. Nijvedt documented a daily hepatic ADMA extraction for more than seven hundred times the amount of plasma ADMA in rats [13]. Serum ADMA is increased in patients with diabetes [14] and in non-diabetic insulin-resistant subjects $[15,16]$, and improvement in insulin resistance is associated to a decrease of ADMA $[17,18]$. Animal models of diabetes, such as db/ $\mathrm{db}$ mice, are widely studied because they reproduce several metabolic and vascular alterations occurring in humans; endothelial dysfunction has been documented in $\mathrm{db} / \mathrm{db}$ mice [19-24], however, to the best of our knowledge, the association of ADMA levels with endothelial dysfunction has not been investigated in this animal model. In this study we assessed plasma, aorta and liver ADMA levels and analyzed endotheliumdependent vascular reactivity in $\mathrm{db} / \mathrm{db}$ mice; furthermore, we examined the effects of silibinin administration on these parameters.

\section{Methods}

\section{Animals and treatments}

All procedures were carried out in accordance with the Italian Guidelines for the Care and Use of Laboratory Animals and with the ARRIVE guidelines [25]. Eightweek-old male BKS.Cg-m+/+ Leprdb/J (db/db) obese mice and eight-week-old male heterozygous $\mathrm{db} / \mathrm{m}$ lean control mice were purchased from Charles River Lab (Calco, Italy). Animals were housed at constant room temperature $\left(23^{\circ} \mathrm{C}\right)(\mathrm{n}=3$ per cage) under 12 hours light/dark cycles with ad libitum access to water and were fed a standard diet. Silibinin dihydrogen disuccinate disodium (Madaus, Köln, Germany) was dissolved in saline which was also used as vehicle for the placebotreated animals. Eighteen mice were distributed in 3 groups: group I $(\mathrm{db} / \mathrm{m}+$ vehicle) included six heterozygous $\mathrm{db} / \mathrm{m}$ mice treated with saline; group II $(\mathrm{db} / \mathrm{db}+$ vehicle) comprised six $\mathrm{db} / \mathrm{db}$ mice treated with saline; group III $(\mathrm{db} / \mathrm{db}+$ silibinin) included six $\mathrm{db} / \mathrm{db}$ mice treated with silibinin $(20 \mathrm{mg} / \mathrm{Kg}$ i.p. injection, daily). At 12 weeks of age, after an overnight fast, animals were anesthetized and sacrificed; blood, aorta and liver samples were obtained for further analysis.

\section{Biochemical analyses}

Blood glucose was measured by Accu-chek (Roche Diagnostics, Milan, Italy). Serum insulin was determined using an automated enzyme immunoassay analyzer from Tosoh (Tokio, Japan). HOMA-IR was calculated as follows: [fasting glucose $(\mathrm{mmol} / \mathrm{L}) \times$ fasting insulin $(\mathrm{mU} /$ L)]/22.5. Plasma and tissue ADMA concentration was determined by using a commercially available enzymelinked immunosorbent assay kit (DLD Diagnostika $\mathrm{GmbH}$, Hamburg, Germany) according to the manufacturer's instructions.

\section{Vasomotor tone}

Aortas were immersed in physiological salt solution (composition, mmol/L: $\mathrm{NaCl}, 118 ; \mathrm{KCl}, 4.6 ; \mathrm{NaHCO}_{3}$, $25 ; \mathrm{MgSO}_{4}, 1.2 ; \mathrm{KH}_{2} \mathrm{PO}_{4}, 1.2 ; \mathrm{CaCl}_{2}, 1.2$; glucose, 10 ; EDTA, 0.025 ; pH 7.4 at $37^{\circ} \mathrm{C}$ ), dissected out of surrounding connective tissue, cut in segments $(2 \mathrm{~mm}$ length) and mounted in a wire myograph (610 M, Danish Myo Technology, Aarhus, Denmark), by using 40 $\mu \mathrm{m}$-diameter stainless steel wire, for isometric record of contractile force. After mounting, each preparation was equilibrated unstretched, for $30 \mathrm{~min}$, in physiologic salt solution, maintained at $37^{\circ} \mathrm{C}$ and aerated with a gas mixture $95 \% \mathrm{O}_{2}-5 \% \mathrm{CO}_{2}$. The normalized passive resting force and the corresponding diameter were then determined for each preparation from its own lengthpressure curve, according to Mulvany and Halpern [26]. Contractile responses were recorded into a computer, by using a data acquisition and recording software (Myodaq and Myodata, Danish Myo Technology). After normalization and 30-min equilibration in physiological solution, the preparations were constricted with isotonic depolarizing $\mathrm{KCl}$ solutions, in which part of $\mathrm{NaCl}$ had been replaced by an equimolar amount of $\mathrm{KCl}$ (composition, mmol/L: $\mathrm{NaCl}, 22.6 ; \mathrm{KCl}, 98.8 ; \mathrm{NaHCO}_{3}, 25$; $\mathrm{MgSO}_{4}, 1.2 ; \mathrm{KH}_{2} \mathrm{PO}_{4}, 1.2 ; \mathrm{CaCl}_{2}, 1.2$; glucose, 10 ; EDTA, $0.025, \mathrm{pH} 7.4$ at $37^{\circ} \mathrm{C}$ ). After washout and $30-$ min recovery, the preparations were exposed to cumulative concentrations of phenilephrine (PE, $1 \mathrm{nmol} / \mathrm{L}-1$ $\mu \mathrm{mol} / \mathrm{L})$. Once the vasoconstriction to $\mathrm{PE}$ had reached steady state, cumulative concentrations of acetylcholine (ACh, $1 \mathrm{nmol} / \mathrm{L}-1 \mu \mathrm{mol} / \mathrm{L}$ ) were added to the organ chamber. Relaxing responses were expressed in percentage of pre-existing contractile tone, induced by PE. After wash out and $30 \mathrm{~min}$ recovery, preparations were exposed to $5 \mathrm{nmol} / \mathrm{L} \mathrm{PE}$, which induced a negligible $(<$ $2 \%$ of $\mathrm{K}^{+} 100$ ) vasoconstriction in lean, but a stronger 
one in $\mathrm{db} / \mathrm{db}\left(17-18 \%\right.$ of $\left.\mathrm{K}^{+} 100\right)$; once PE-induced tone had reached a steady state, preparations were challenged with cumulative concentrations of asymmetric $\mathrm{N}^{\mathrm{G}}, \mathrm{N}^{\mathrm{G}}$. dimethyl-L-arginine (ADMA, $300 \mathrm{nmol} / \mathrm{L}$ - $300 \mu \mathrm{mol} /$ L). Preparations were then further constricted by 1 $\mu \mathrm{mol} / \mathrm{L} \mathrm{PE}$ in the presence of $100 \mu \mathrm{mol} / \mathrm{L} \mathrm{N}^{\mathrm{G}}$-nitro-Larginine (LNNA), once PE-induced tone had reached a steady state, preparations were challenged with cumulative concentrations of sodium nitroprusside (SNP, 1 $\mathrm{nmol} / 1 \mathrm{~L}-1 \mu \mathrm{mol} / \mathrm{L}$ ), to assess endothelium-independent vasodilatation. PE, ACh, SNP, LNNA and ADMA were from Sigma (St. Louis, MO, U.S.A.); $10 \mathrm{mmol} / \mathrm{L}$ stock solutions were prepared in water and further diluted in physiological salt solution as required, except for ADMA, which was dissolved in water as $30 \mathrm{mmol} / \mathrm{L}$ stock solution. Concentration-response curves to vasoactive agonists were plotted as response (for vasoconstrictors, in \% of vasoconstriction induced by $\mathrm{KCl}$ in the same arteries; for vasodilators in \% of residual tone) against log molar concentration of drug. Each set of data points was curve-fitted by a non-linear regression, best-fit, sigmoid dose-response curve with no constraints, with the use of Graph Pad Prism (Graph Pad Software, San Diego, CA). Pharmacological parameters (concentration producing $50 \%$ of maximum effect or $\mathrm{EC}_{50}$ and maximum effect or $\mathrm{E}_{\max }$ ) were calculated from these non-linear fits. Each curve represents 12 preparations from 6 different mice.

\section{Statistical analysis}

Statistics were aided by Graph Pad Prism. All results were expressed as mean \pm standard error of mean (S.E. M.). P values less than 0.05 were considered significant. Biochemical data were analyzed by one-way ANOVA with Bonferroni Post-Hoc analysis. Concentrationresponse curve from isolated aortas were compared by two-way ANOVA.

\section{Results}

\section{Metabolic parameters}

All $\mathrm{db} / \mathrm{db}$ mice weighted more than lean controls at week 8 , before starting the treatment; silibinin administration did not significantly change body weight or food intake (data not shown). Untreated $\mathrm{db} / \mathrm{db}$ were insulin resistant, as shown by HOMA-IR; silibinin decreased fasting glucose and insulin, reversing insulin resistance (Table 1).

\section{Plasma, aorta and liver ADMA levels}

Plasma ADMA levels were higher in $d b / d b$ than in $d b /$ $\mathrm{m}$ (Figure 1A). Silibinin reduced plasma ADMA in $\mathrm{db} /$ $\mathrm{db}$ to a level lower than in $\mathrm{db} / \mathrm{m}$ animals. These differences in ADMA levels were even more pronounced in aorta, where, again, ADMA was higher in $\mathrm{db} / \mathrm{db}$
Table 1 Biometric and biochemical parameters

\begin{tabular}{llll}
\hline & $\begin{array}{l}\mathrm{db} / \mathrm{m}+ \\
\text { vehicle }\end{array}$ & $\begin{array}{l}\mathrm{db} / \mathrm{db}+ \\
\text { vehicle }\end{array}$ & $\begin{array}{l}\mathrm{db} / \mathrm{db}+ \\
\text { silibinin }\end{array}$ \\
\hline $\begin{array}{l}\text { 8-weeks weight } \\
\text { (g) }\end{array}$ & $22.5 \pm 0.5$ & $33.0 \pm 2.2^{*}$ & $32.5 \pm 2.7^{*}$ \\
\hline $\begin{array}{l}\text { 12-weeks weight } \\
\text { (g) }\end{array}$ & $25.6 \pm 1.2$ & $38.4 \pm 1.8^{*}$ & $36.8 \pm 1.9^{*}$ \\
\hline $\begin{array}{l}\text { Blood glucose } \\
\text { (mg/dL) }\end{array}$ & $68.2 \pm 7.6$ & $220.8 \pm 40.2^{* *}$ & $112.7 \pm 22.8^{\dagger}$ \\
\hline $\begin{array}{l}\text { Serum insulin } \\
\text { (mU/L) }\end{array}$ & $6.8 \pm 1.2$ & $10.3 \pm 0.8^{* *}$ & $7.5 \pm 1.1^{\dagger}$ \\
\hline \begin{tabular}{l} 
HOMA-IR \\
\hline *P $<0.05, * * P<0.01$
\end{tabular} & $1.1 \pm 0.2$ & $5.6 \pm 0.5^{* *}$ & $2.1 \pm 0.3^{\dagger \dagger}$ \\
db + vehicle. & & & \\
\hline
\end{tabular}

compared to $\mathrm{db} / \mathrm{m}$ and was reduced by silibinin in $\mathrm{db} /$ $\mathrm{db}$ mice, by more than 50\% (Figure $1 \mathrm{~B}$ ). Liver ADMA was slightly lower in $\mathrm{db} / \mathrm{db}$ as compared to lean controls, although the difference was not statistically significant, whereas silibinin led to raised ADMA in hepatic tissue (Figure 1C). Plasma and aorta ADMA levels were positively correlated (Figure 1D); by contrast, liver ADMA was inversely correlated with both plasma and aorta ADMA concentrations (Figure 1E).

\section{Vascular tone}

Contractile tone induced by high $\mathrm{K}^{+}$was higher in aorta preparations from $\mathrm{db} / \mathrm{db}$ than in $\mathrm{db} / \mathrm{m}$ mice and was not influenced by silibinin treatment $(\mathrm{db} / \mathrm{m}+$ vehicle, $3.42 \pm 0.25 \mathrm{mN} / \mathrm{mm} ; \mathrm{db} / \mathrm{db}+$ vehicle, $4.33 \pm 0.35 \mathrm{mN} /$ $\mathrm{mm} ; \mathrm{db} / \mathrm{db}+$ silibinin, $4.36 \pm 0.27 \mathrm{mN} / \mathrm{mm} ; \mathrm{db} / \mathrm{m}+$ vehicle versus all $\mathrm{db} / \mathrm{db}, \mathrm{P}<0.05)$.

Vasoconstriction to $\mathrm{PE}$, either expressed as raw values $\left(\mathrm{mN} / \mathrm{mm}\right.$, not shown) or normalized in $\%$ of $\mathrm{K}^{+}$-induced contraction (Figure 2A and Table 2) was also higher in $\mathrm{db} / \mathrm{db}$; in particular concentration-contraction curve to $\mathrm{PE}$ was displaced to the left in $\mathrm{db} / \mathrm{db}$ mice, in a parallel manner. Vasoconstriction to PE was not modified by silibinin administration. Endothelium-dependent vasodilatation to $\mathrm{ACh}$ and, to a less extent, endothelium-independent vasodilatation to SNP were lower in $\mathrm{db} / \mathrm{db}$ mice as compared to lean animals (Figure 2B, C and Table 2); vasodilatation to $\mathrm{ACh}$ was significantly increased by silibinin, whereas endothelium-independent vasodilatation to SNP was not modified by the treatment. In vitro challenge with ADMA induced a stronger contractile tone in aorta from $\mathrm{db} / \mathrm{db}$ mice than in $\mathrm{db} / \mathrm{m}$ (Figure 2D); of note, the tone induced by applying ADMA in vitro in aorta from $\mathrm{db} / \mathrm{db}$ mice, was not influenced by in vivo silibinin.

\section{Discussion}

Endothelial dysfunction plays a pivot role in the initiation of the cascade of events leading to CVD [3]. 
A

Plasma ADMA

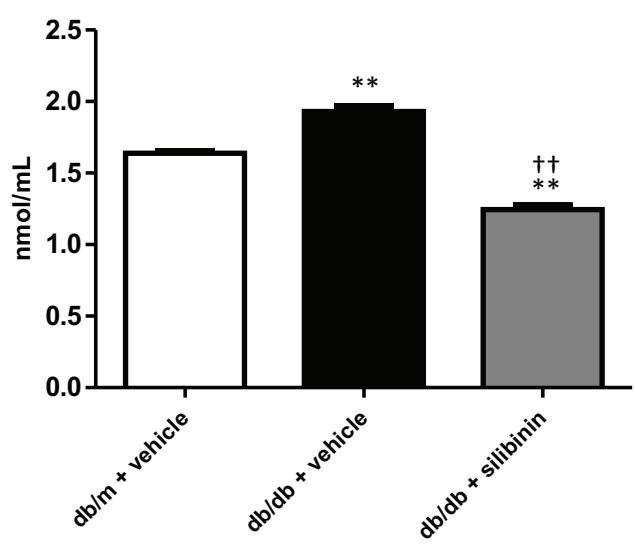

C

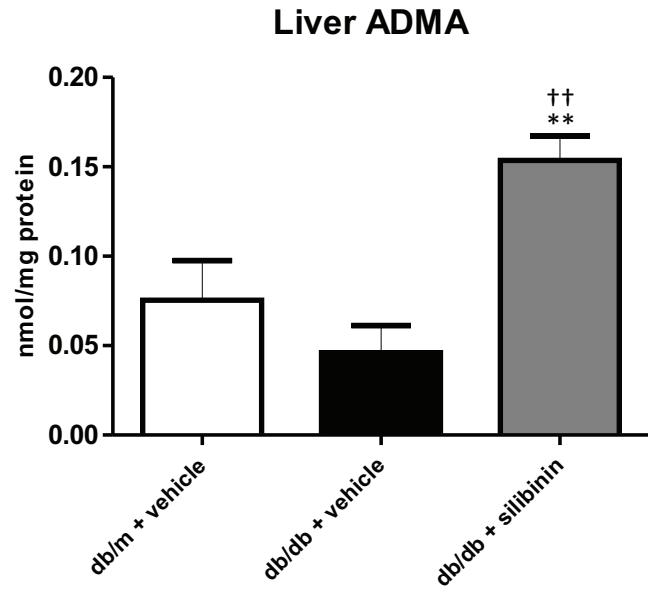

E

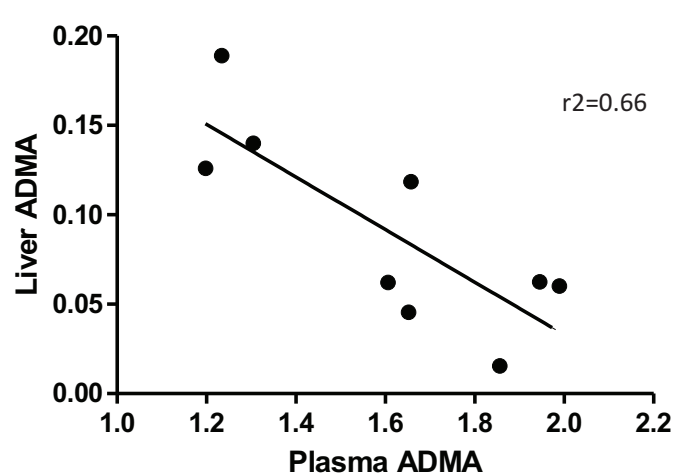

B

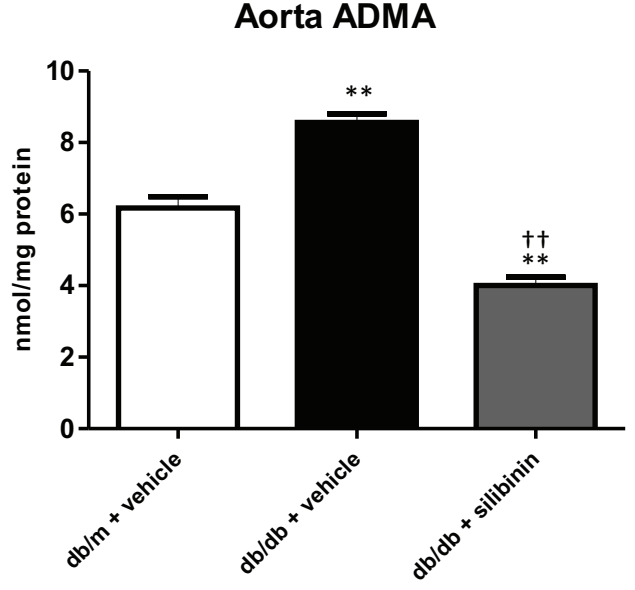

D

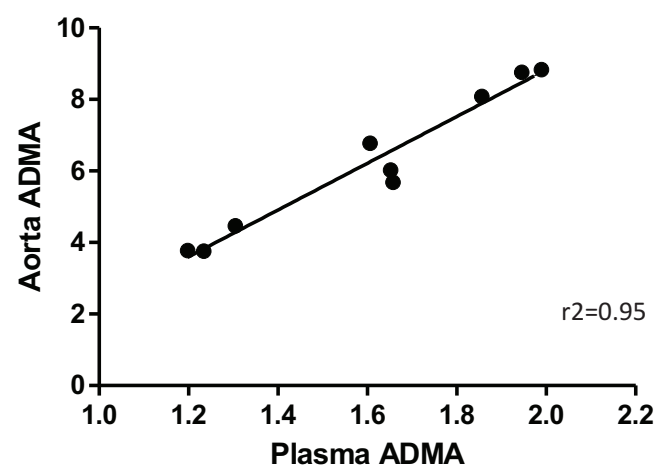

$\mathbf{F}$

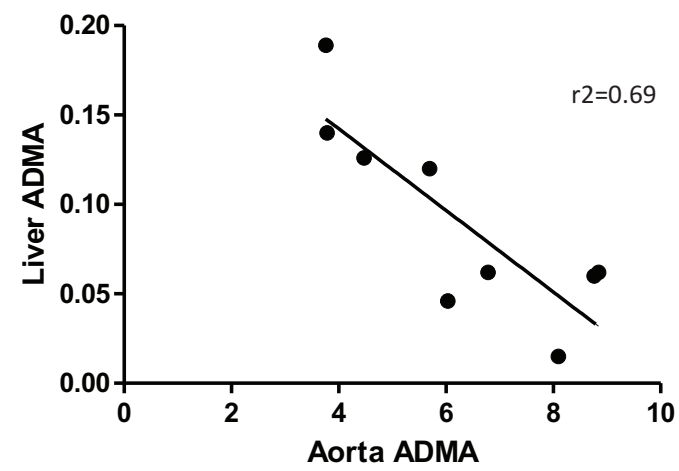

Figure 1 Plasma, aorta and liver ADMA levels. (A) Plasma ADMA was higher in $\mathrm{db} / \mathrm{db}$ mice than lean controls and was significantly decreased by silibinin administration. (B) Aorta ADMA was similarly higher in untreated $\mathrm{db} / \mathrm{db}$ mice and was markedly decreased in mice treated with silibinin. (C) Liver ADMA was increased in the silibinin group. (D) Plasma and aorta ADMA levels exhibited a positive correlation ( $\mathrm{r} 2=0.95$, $P<0.0001)$. ( $E, F)$ Liver ADMA levels were inversely related to both plasma ADMA $(r 2=0.66, P<0.01)$ and aorta $A D M A(r 2=0.69, P<0.01)$. ${ }^{*} P<0.01$ versus $\mathrm{db} / \mathrm{m}+$ vehicle; $++P<0.01$ versus $\mathrm{db} / \mathrm{db}+$ vehicle. 


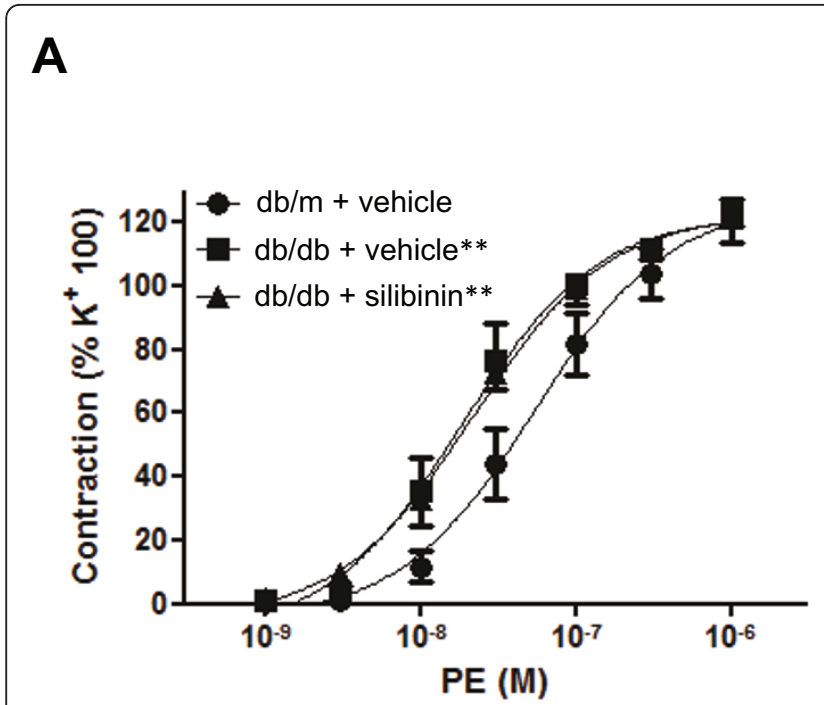

C

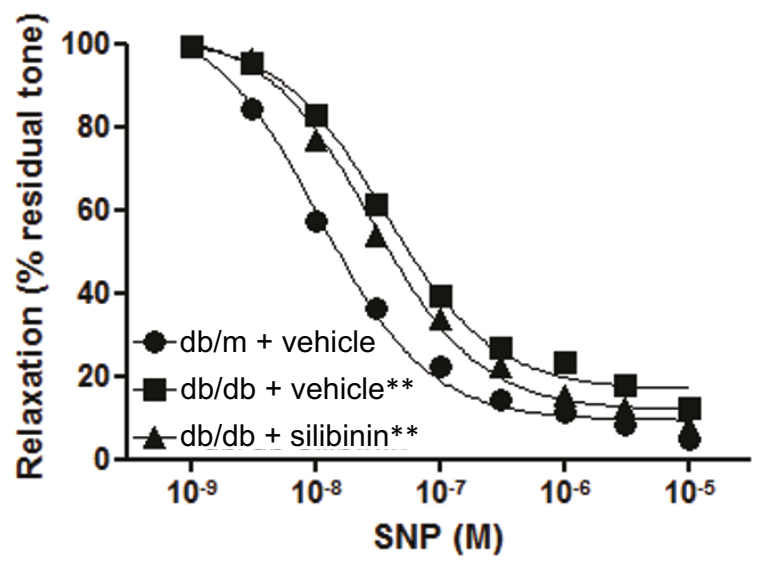

B

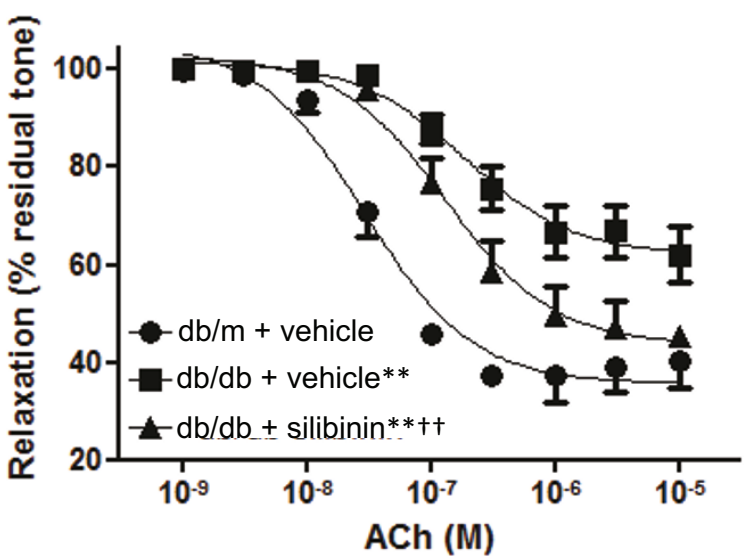

D

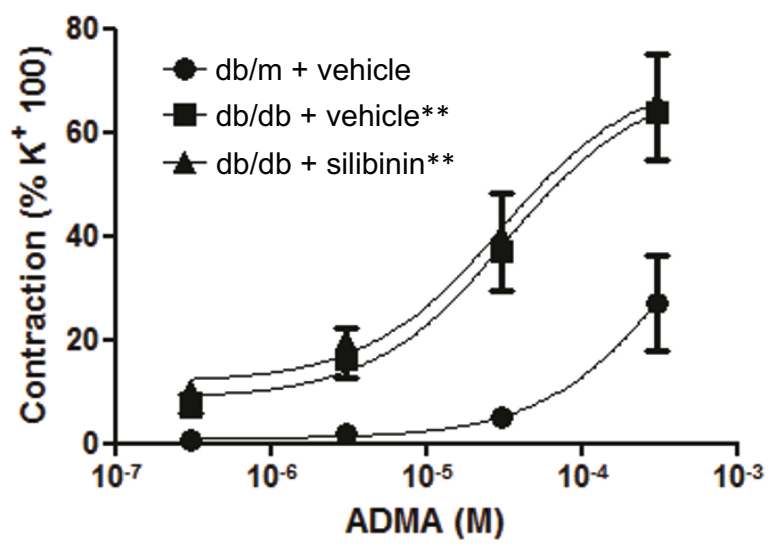

Figure 2 Vasomotor responses in isolated aorta. (A) Vasoconstriction to phenilephrine (PE); (B) vasodilatation to acetylcholine (ACh); (C) vasodilatation to sodium nitroprusside (SNP); (D) vasoconstriction to asymmetric $N^{G}, N^{G}$-dimethyl-L-arginine (ADMA). Vasoconstriction is expressed in \% of high $\mathrm{K}^{+}$-induced tone in the same preparation; vasodilatation is expressed as residual tone in \% of PE-induced preconstriction. ${ }^{* *} \mathrm{P}<0.01$ versus $\mathrm{db} / \mathrm{m}+$ vehicle; ${ }^{+\dagger} \mathrm{P}<0.01$ versus $\mathrm{db} / \mathrm{db}+$ vehicle.

ADMA is an eNOS inhibitor whose levels rise in a number of pathological conditions associated with endothelial dysfunction, including diabetes, dyslipidemia and obesity $[9,10]$. In type 2 diabetes, ADMA levels are associated with macrovascular diseases independently of traditional cardiovascular risk factors [15] and ADMA pathway has been proposed as a link between inflammation and endothelial dysfunction [27].

In this study, we report, for the first time, the association of ADMA levels with endothelial dysfunction in $\mathrm{db} / \mathrm{db}$ mice and demonstrated that silibinin, a worldwide-used flavolignan from milk thistle, favorably impacts on ADMA levels and improves endothelial dysfunction. We found that $\mathrm{db} / \mathrm{db}$ mice exhibit, both in plasma and aorta, ADMA levels higher than $\mathrm{db} / \mathrm{m}$ mice. In silibinin-treated $\mathrm{db} / \mathrm{db}$, the substantial reduction of plasma and vascular ADMA is associated with the improvement of insulin resistance; this is in accordance with data in humans indicating that serum ADMA predicts the degree of insulin sensitivity [16]. Interestingly, circulating ADMA is not related to brachial artery-flow mediated dilatation in patients with type 1 diabetes [28]. The pathways involved in the beneficial effect of silibinin on insulin resistance are not known; however, a possible explanation for the decrease in blood glucose levels in treated animals may be the inhibition of liver 
Table 2 Pharmacological parameters of vasomotor responses to phenilephrine (PE), acetylcholine (Ach), sodium nitroprusside (SNP) and asymmetric $\mathbf{N}^{\mathbf{G}}, \mathbf{N}^{\mathbf{G}}-$ dimethyl-L-arginine (ADMA) in isolated aorta

\begin{tabular}{|c|c|c|c|}
\hline \multicolumn{4}{|c|}{$\mathrm{PE}$} \\
\hline & $\mathrm{pD}_{2}$ & $\mathrm{EC}_{50}(\mathrm{nmol} / \mathrm{L})$ & $E_{\max }\left(\% K^{+}\right)$ \\
\hline $\mathrm{db} / \mathrm{m}+$ vehicle & $7.27 \pm 0.11$ & $53.7(32.1-89.7)$ & $126.0 \pm 7.0$ \\
\hline $\mathrm{db} / \mathrm{db}+$ vehicle & $7.74 \pm 0.10^{* *}$ & $18.3(11.3-29.9)$ & $122.3 \pm 5.0$ \\
\hline $\mathrm{db} / \mathrm{db}+$ silibinin & $7.66 \pm 0.08^{* *}$ & $21.7(15.3-30.7)$ & $122.6 \pm 3.7$ \\
\hline \multicolumn{4}{|c|}{ ADMA } \\
\hline & $\mathrm{pD}_{2}$ & $\mathrm{EC}_{50}(\mu \mathrm{mol} / \mathrm{L})$ & $\mathrm{E}_{\max }\left(\% \mathrm{~K}^{+}\right)$ \\
\hline $\mathrm{db} / \mathrm{m}+$ vehicle & $3.36 \pm 1.76$ & $440\left(0.1-10^{6}\right)$ & $65.6( \pm 154)$ \\
\hline $\mathrm{db} / \mathrm{db}+$ vehicle & $4.48 \pm 0.36^{* *}$ & $32.8(5.8-188)$ & $69.6 \pm 12.0$ \\
\hline $\mathrm{db} / \mathrm{db}+$ silibinin & $4.51 \pm 0.40^{* *}$ & $30.1(4.8-194)$ & $71.2 \pm 12.6$ \\
\hline \multicolumn{4}{|c|}{$\mathrm{ACh}$} \\
\hline & $\mathrm{pD}_{2}$ & $\mathrm{EC}_{50}(\mathrm{nmol} / \mathrm{L})$ & $\mathrm{E}_{\max }(\%$ tone $)$ \\
\hline $\mathrm{db} / \mathrm{m}+$ vehicle & $7.54 \pm 0.12$ & $28.8(16.7-49.5)$ & $35.7 \pm 2.5$ \\
\hline $\mathrm{db} / \mathrm{db}+$ vehicle & $6.74 \pm 0.15^{* *}$ & $183(90.2-372)$ & $62.1 \pm 2.1^{* *}$ \\
\hline $\mathrm{db} / \mathrm{db}+$ silibinin & $6.89 \pm 0.12^{* *}$ & $130(74.9-224)$ & $43.7 \pm 2.8^{+\dagger}$ \\
\hline \multicolumn{4}{|c|}{ SNP } \\
\hline & $\mathrm{pD}_{2}$ & $\mathrm{EC}_{50}(\mathrm{nmol} / \mathrm{L})$ & $E_{\max }(\%$ tone $)$ \\
\hline $\mathrm{db} / \mathrm{m}+$ vehicle & $7.97 \pm 0.04$ & $10.1(8.8-12.9)$ & $9.4 \pm 1.0$ \\
\hline $\mathrm{db} / \mathrm{db}+$ vehicle & $7.45 \pm 0.06^{* *}$ & $35.7(26.5-48.0)$ & $16.7 \pm 1.7^{*}$ \\
\hline $\mathrm{db} / \mathrm{db}+$ silibinin & $7.56 \pm 0.05^{* *}$ & $27.7(21.7-35.3)$ & $11.8 \pm 1.5$ \\
\hline
\end{tabular}

Pharmacological parameters are from non linear regression; $\mathrm{pD}_{2}$ is the negative logarithm of the concentration producing $50 \%$ of the maximum effect, $\mathrm{EC}_{50}$ is the concentration producing $50 \%$ of maximum effect $(95 \%$ confidence limits are given in parenthesis), $E_{\max }$ is the maximum effect (vasoconstriction to PE or ADMA in \% of vasoconstriction evoked in the same preparations by $100 \mathrm{mmol} / \mathrm{L} \mathrm{K}^{+}$; vasodilatation to $\mathrm{ACh}$ or SNP as $\%$ of residual tone). Statistical comparisons were made on the whole curves by two-way ANOVA; $\mathrm{n}=12$ preparations from 6 mice in each group; ${ }^{*} \mathrm{P}<0.05$, ${ }^{* *} \mathrm{P}<0.01$ versus $\mathrm{db} / \mathrm{m}+$ vehicle, ${ }^{+\dagger} \mathrm{P}<0.01$ versus $\mathrm{db} / \mathrm{db}+$ vehicle.

gluconeogenesis [29]. The molecular link between insulin signaling and ADMA homeostasis is poorly understood at present; data obtained in endothelial cells suggest that insulin and adiponectin modulate the activity of DDAH [30]. Of note, DDAH gene variants influence the risk of diabetes and its complications [31].

Vascular endothelium is not the only contributor to regulation of plasma ADMA levels [12], and the role of other tissues and organs in ADMA metabolism remains to be elucidated. Interestingly, in this study we found not only a positive correlation between plasma and vascular ADMA, but also an inverse correlation between liver and both plasma and aorta ADMA. The molecular basis for the observed correlations is not clear; we can speculate that the increase of hepatic ADMA in $\mathrm{db} / \mathrm{db}$ mice induced by silibinin may involve the system of $\mathrm{y}^{+}$ carriers of the cationic amino acid family, which has been shown to play a relevant role in the clearance of dimethylarginines in the liver [32]. In this respect, further studies in mice with diet-induced obesity/diabetes might be helpful. Similarly, the role of kidney in
ADMA clearance should also be elucidated, although previous findings, showing that ADMA clearance is conserved in nephrectomized mice [33], indicate that it may be less substantial.

Our observation of impaired endothelium-dependent vasodilatation to $\mathrm{ACh}$ in $\mathrm{db} / \mathrm{db}$ mice is consistent with previous reports [19-24]. Moreover, we found that endothelium-dependent vasodilatation of isolated aorta to $\mathrm{ACh}$ was improved by silibinin in $\mathrm{db} / \mathrm{db}$ mice; because silibinin reduced ADMA levels in aorta, the subsequent reduction of NOS inhibition by ADMA may, at least in part, account for the observed improvement of endothelium-dependent vasodilatation. Surprisingly, despite the effect on aorta ADMA levels, silibinin did not modify in vitro vascular responsiveness to either PE or high $\mathrm{K}^{+}$. Enhanced vasoconstriction to $\alpha$-adrenergic stimulation has been attributed to reduced basal nitric oxide production in $\mathrm{db} / \mathrm{db}$ mice [19]; since silibinin did not change the concentration-response curve to PE, additional mechanisms, other than increase in ADMA levels, must be postulated for the reduced basal NO production in $\mathrm{db} / \mathrm{db}$ mice; among them, free radical generation has been documented and may play an important role. Increased generation of oxygen free radicals is supposed to increase NO scavenging (with production of reactive species such as peroxynitrite), thereby reducing the vasodilator effectiveness of endogenous or exogenous (from NO-donor drugs) NO. In accordance with this hypothesis, endothelium-independent vasodilatation to SNP has also been shown to be reduced in $\mathrm{db} / \mathrm{db}$ mice [23]. Here we confirm this latter issue, showing a slight, but significant, displacement to the right of the concentration-response curve to SNP in $\mathrm{db} / \mathrm{db}$ mice. Because SNP is a NOdonor, reduced sensitivity to SNP implies reduced sensitivity to $\mathrm{NO}$ and/or increased $\mathrm{NO}$ scavenging in $\mathrm{db} / \mathrm{db}$ vessels. Of note, the reduced responsiveness to SNP in $\mathrm{db} / \mathrm{db}$ mice was not changed by silibinin treatment. Such a reduced sensitivity to $\mathrm{NO}$ in $\mathrm{db} / \mathrm{db}$ vessels may also, at least in part, account for the reduced vasodilatation to $\mathrm{ACh}$; however, the fact that silibinin improved the response to $\mathrm{ACh}$, while not changing the response to SNP, would indicate that in silibinin-treated animals ACh-induced NO production was increased, possibly because endogenous ADMA was reduced, leading to increased NOS activity. Finally, when applied in vitro, ADMA elicited the same contractile response in the two groups of $\mathrm{db} / \mathrm{db}$ mice, regardless of the treatment, suggesting that silibinin in vivo may inhibit ADMA production rather than enhance its vascular degradation.

\section{Conclusions}

In conclusion, in this study we showed that plasma ADMA levels are increased in $\mathrm{db} / \mathrm{db}$ animals similarly to diabetic patients. The increased ADMA levels are 
associated to endothelial dysfunction in $\mathrm{db} / \mathrm{db}$. Silibinin treatment reversed plasma and aorta ADMA increase and improved both endothelial dysfunction and insulin resistance. These pharmacological properties of silibinin are of potential clinical interest given its favorable safety profile.

\section{List of abbreviations}

CVD: cardiovascular diseases; NO: nitric oxide; ADMA: asymmetric $N^{G}: N^{G}$ dimethyl-L-arginine; NOS: nitric oxide synthase; eNOS: endothelial nitric oxide synthase; DDAH: dimethylarginine hydrolase; HOMA: homeostasis model of assessment; IR: insulin resistance; PE: phenilephrine; Ach: acetylcholine; SNP: sodium nitroprusside.

\section{Acknowledgements}

SS was supported by a grant of Italian Ministry of University, PRIN 2007SXKWSA_001.

\section{Author details}

'Department of Drug Sciences, University of Catania, Catania, Italy. ${ }^{2}$ Department of Cardiac Surgery, San Donato Institute, San Donato Milanese (MI), Italy. ${ }^{3}$ Department of Clinical and Molecular Biomedicine, University of Catania, Catania, Italy. ${ }^{4}$ Department of Internal Medicine, University of Catania, Catania, Italy.

\section{Authors' contributions}

GLV conceived and designed the study, performed experiments, analyzed data and contributed to the writing of the manuscript; SS designed the study, performed experiments and contributed to the writing of the manuscript; VS performed experiments, analyzed data and critically reviewed the manuscript; AM analyzed data and critically reviewed the manuscript; VU performed experiments and analyzed data; IS performed experiments and analyzed data; FG analyzed data and critically reviewed the manuscript; FS conceived and designed the study, performed experiments, analyzed data and contributed to the writing of the manuscript.

All authors read and approved the final manuscript.

\section{Competing interests}

The authors declare that they have no competing interests.

Received: 20 April 2011 Accepted: 14 July 2011 Published: 14 July 2011

\section{References}

1. Mottillo S, Filion KB, Genest J, Joseph L, Pilote L, Poirier P, Rinfret S, Schiffrin EL, Eisenberg MJ: The metabolic syndrome and cardiovascular risk a systematic review and meta-analysis. J Am Coll Cardiol 2010, 56:1113-1132.

2. Reriani MK, Lerman LO, Lerman A: Endothelial function as a functional expression of cardiovascular risk factors. Biomark Med 2010, 4:351-360.

3. Sima AV, Stancu CS, Simionescu M: Vascular endothelium in atherosclerosis. Cell Tissue Res 2009, 335:191-203.

4. Manach C, Mazur A, Scalbert A: Polyphenols and prevention of cardiovascular diseases. Curr Opin Lipidol 2005, 16:77-84.

5. Wang YK, Hong YJ, Huang ZQ: Protective effects of silybin on human umbilical vein endothelial cell injury induced by $\mathrm{H}_{2} \mathrm{O} 2$ in vitro. Vascul Pharmacol 2005, 43:198-206.

6. Elahi MM, Kong YX, Matata BM: Oxidative stress as a mediator of cardiovascular disease. Oxid Med Cell Longev 2009, 2:259-269.

7. Jin JS, D'Alecy LG: Central and peripheral effects of asymmetric dimethylarginine, an endogenous nitric oxide synthetase inhibitor. $J$ Cardiovasc Pharmacol 1996, 28:439-446.

8. Ito A, Tsao PS, Adimoolam S, Kimoto M, Ogawa T, Cooke JP: Novel mechanism for endothelial dysfunction: dysregulation of dimethylarginine dimethylaminohydrolase. Circulation 1999, 99:3092-3095.

9. Nanayakkara PW, Teerlink T, Stehouwer CD, Allajar D, Spijkerman A, Schalkwijk C, ter Wee PM, van Guldener C: Plasma asymmetric dimethylarginine (ADMA) concentration is independently associated with carotid intima-media thickness and plasma soluble vascular cell adhesion molecule-1 (sVCAM-1) concentration in patients with mild-tomoderate renal failure. Kidney Int 2005, 68:2230-2236.

10. Boger RH, Bode-Boger SM, Thiele W, Junker W, Alexander K, Frolich JC: Biochemical evidence for impaired nitric oxide synthesis in patients with peripheral arterial occlusive disease. Circulation 1997, 95:2068-2074.

11. Tran CT, Leiper JM, Vallance P: The DDAH/ADMA/NOS pathway. Atheroscler Suppl 2003, 4:33-40.

12. Wilcken DE, Sim AS, Wang J, Wang XL: Asymmetric dimethylarginine (ADMA) in vascular, renal and hepatic disease and the regulatory role of L-arginine on its metabolism. Mol Genet Metab 2007, 91:309-317.

13. Nijveldt RJ, Teerlink T, Siroen MP, van Lambalgen AA, Rauwerda JA, van Leeuwen PA: The liver is an important organ in the metabolism of asymmetrical dimethylarginine (ADMA). Clin Nutr 2003, 22:17-22

14. Kimoto M, Whitley GS, Tsuji H, Ogawa T: Detection of NG, NGdimethylarginine dimethylaminohydrolase in human tissues using a monoclonal antibody. J Biochem 1995, 117:237-238.

15. Fard A, Tuck CH, Donis JA, Sciacca R, Di Tullio MR, Wu HD, Bryant TA, Chen NT, Torres-Tamayo M, Ramasamy R, et al: Acute elevations of plasma asymmetric dimethylarginine and impaired endothelial function in response to a high-fat meal in patients with type 2 diabetes. Arterioscler Thromb Vasc Biol 2000, 20:2039-2044.

16. Nash DT: Insulin resistance, ADMA levels, and cardiovascular disease. JAMA 2002, 20;287:1451-1452.

17. Marliss EB, Chevalier S, Gougeon R, Morais JA, Lamarche M, Adegoke OA, Wu G: Elevations of plasma methylarginines in obesity and ageing are related to insulin sensitivity and rates of protein turnover. Diabetologia 2006, 49:351-359

18. McLaughlin T, Stuhlinger M, Lamendola C, Abbasi F, Bialek J, Reaven GM, Tsao PS: Plasma asymmetric dimethylarginine concentrations are elevated in obese insulin-resistant women and fall with weight loss. J Clin Endocrinol Metab 2006, 91:1896-1900.

19. Kamata K, Kojima S: Characteristics of contractile responses of aorta to norepinephrine in db/db mice. Res Commun Mol Pathol Pharmacol 1997, 96:319-328.

20. Piercy V, Taylor SG: A comparison of spasmogenic and relaxant responses in aortae from C57/BL/KsJ diabetic mice with those from their nondiabetic litter mates. Pharmacology 1998, 56:267-275.

21. Lagaud GJ, Masih-Khan E, Kai S, van Breemen C, Dube GP: Influence of type II diabetes on arterial tone and endothelial function in murine mesenteric resistance arteries. J Vasc Res 2001, 38:578-589.

22. Elmi S, Sallam NA, Rahman MM, Teng X, Hunter AL, Moien-Afshari F, Khazaei M, Granville DJ, Laher I: Sulfaphenazole treatment restores endothelium-dependent vasodilation in diabetic mice. Vascul Pharmacol 2008, 48:1-8.

23. Miike T, Kunishiro K, Kanda M, Azukizawa S, Kurahashi K, Shirahase H: Impairment of endothelium-dependent $\mathrm{ACh}$-induced relaxation in aorta of diabetic $\mathrm{db} / \mathrm{db}$ mice-possible dysfunction of receptor and/or receptor-G protein coupling. Naunyn Schmiedebergs Arch Pharmacol 2008, 377:401-410.

24. Nuno DW, Harrod JS, Lamping KG: Sex-dependent differences in Rho activation contribute to contractile dysfunction in type 2 diabetic mice. Am J Physiol Heart Circ Physiol 2009, 297:H1469-H1477.

25. Kilkenny C, Browne WJ, Cuthill IC, Emerson M, Altman DG: Improving bioscience research reporting: the ARRIVE guidelines for reporting animal research. PLOS Biol 2010, 8:e1000412.

26. Mulvany MJ, Halpern W: Contractile properties of small arterial resistance vessels in spontaneously hypertensive and normotensive rats. Circ Res 1977, 41:19-26.

27. Antoniades C, Demosthenous M, Tousoulis D, Antonopoulos AS, Vlachopoulos C, Toutouza M, Marinou K, Bakogiannis C, Mavragani K, Lazaros $\mathrm{G}$, et al: Role of asymmetrical dimethylarginine in inflammationinduced endothelial dysfunction in human atherosclerosis. Hypertension 2011, 58:93-98

28. Sibal L, Agarwal SC, Schwedhelm E, Luneburg N, Boger RH, Home PD: A study of endothelial function and circulating asymmetric dimethylarginine levels in people with Type 1 diabetes without macrovascular disease or microalbuminuria. Cardiovasc Diabetol 2009, 8:27.

29. Guigas B, Naboulsi R, Villanueva GR, Taleux N, Lopez-Novoa JM, Leverve XM, El-Mir MY: The flavonoid silibinin decreases glucose-6-phosphate 
hydrolysis in perfused rat hepatocytes by an inhibitory effect on glucose-6-phosphatase. Cell Physiol Biochem 2007, 20:925-934.

30. Anderssohn M, Schwedhelm E, Luneburg N, Vasan RS, Boger RH:

Asymmetric dimethylarginine as a mediator of vascular dysfunction and a marker of cardiovascular disease and mortality: an intriguing interaction with diabetes mellitus. Diab Vasc Dis Res 2010, 7:105-118.

31. Lu TM, Lin SJ, Lin MW, Hsu CP, Chung MY: The association of dimethylarginine dimethylaminohydrolase 1 gene polymorphism with type 2 diabetes: a cohort study. Cardiovasc Diabetol 2011, 10:16.

32. Siroen MP, van der Sijp JR, Teerlink T, van SC, Nijveldt RJ, van Leeuwen PA: The human liver clears both asymmetric and symmetric dimethylarginine. Hepatology 2005, 41:559-565.

33. Carello KA, Whitesall SE, Lloyd MC, Billecke SS, D'Alecy LG: Asymmetrical dimethylarginine plasma clearance persists after acute total nephrectomy in rats. Am J Physiol Heart Circ Physiol 2006, 290:H209-H216.

doi:10.1186/1475-2840-10-62

Cite this article as: Li Volti et al:: Effect of silibinin on endothelial dysfunction and ADMA levels in obese diabetic mice. Cardiovascular Diabetology 2011 10:62.

\section{Submit your next manuscript to BioMed Central} and take full advantage of:

- Convenient online submission

- Thorough peer review

- No space constraints or color figure charges

- Immediate publication on acceptance

- Inclusion in PubMed, CAS, Scopus and Google Scholar

- Research which is freely available for redistribution

Submit your manuscript at www.biomedcentral.com/submit 